\title{
Investigation on the Rheological Behavior of Multigrade Oil under the Effect of Organic and Inorganic Impurities
}

\author{
Brahim Belahcene \\ Faculty of Technology, Department \\ of Mechanical Engineering \\ LAEPO Research Laboratory \\ Tlemcen, Algeria \\ belahcene.brahim@gmail.com
}

\author{
Ali Mansri \\ Faculty of Science, Department \\ of Chemistry \\ LAEPO Research Laboratory \\ Tlemcen, Algeria \\ a_mansri@mail.univ-tlemcen.dz
}

\author{
Abderrahim Benmoussat \\ Faculty of Technology, Department \\ of Mechanical Engineering \\ LAEPO Research Laboratory \\ Tlemcen, Algeria \\ abbenmoussa@gmail.com
}

\begin{abstract}
The lubrication process of mechanical equipment and treatment of assembly metals structures using fluids with efficient rheological properties requires a knowledge of their behavior in the presence and in the absence of organic impurities. The intrinsic physical property of the lubricating fluids has a dependency to the mechanical and physicochemical environment. This paper is focused on the assessment of the behavior of SAE20W40 multigrade oil under normal temperature and pressure, through the addition of water in vapor phase and solid paraffin. Results show that there is a decrease in the dynamic and kinematic viscosity for heterogeneous oils. The rate of degradation is greater in the mixture of water with oil. The addition of paraffin in the mixture caused an increase in viscosity. However, after certain RPM points, it is noted that the data curve became similar to the first mixture. This relaxation phenomenon is caused by the turbulence created by the rotating cylinder in oil. The use of a retentate paraffin shows that the added agent has acted as a surfactant.
\end{abstract}

Keywords- Viscosity; oil; water; relaxation; paraffin; miscibility

\section{INTRODUCTION}

The mix of raw materials into oil, e.g. industrial oils, requires a continuous process of monitoring their behavior before and after their implementation in service. In the field of oil production, three main methods are applied:

- compression of the material, i.e. to crush some cold or hot petroleum products, to extract the oil

- distilling, i.e. heating of the material for the separation of oil from other ingredients.

- chemical synthesis, i.e. to manufacture an oil through reaction with chemical reagents.

Each fluid is characterized by a dynamic viscosity represented by the ratio of shear stress to shear rate, which is perpendicular to the plane of shear. The latter becomes an intrinsic characteristic; if it is divided by the density $\rho$ fluid, it gives the kinematic viscosity 0 [1]. The viscosity index VI was first proposed in 1929 [2] and it was revised in 1945 [3].
The classification of the Society of Automotive Engineers (SAE) used particularly in the automotive industry classifies oils according to their viscosity, and defines continuous intervals of viscosity with a minimum and a maximum (SAE 0W, SAE 5W, SAE 10W30, SAE 20W40 etc).

An empirical relationship showing the relationship between the viscosity ( $v$ in $\mathrm{cSt}$ ) and the temperature ( $\mathrm{T}$ in Kelvin) is given in $[2,3,8-11]$ and it uses two positive constants (A and $\mathrm{B})$ related to the nature of the oil. In general, the presence of water molecules in lubricating oils or and its derivatives is an important issue for their physico-chemical properties. A phase of different properties relative to the fluid source, may be added (phase contamination). The separation of this new phase occurs slowly by natural settling, due to density differences. The effective viscosity of the oil-water mixture, depends on several parameters such as the volume fraction of the dispersed phase and the temperature [4]. A study of the variation of the relative viscosity of oil-water mixture as a function of the volume fraction and temperature $\mathrm{V}$ is performed in [5]. The thermodynamic model that shows the relationship between the relative viscosity and the volume fraction can be found in [912]. The relative viscosity has a relationship with the volume fraction and the ratio between the viscosity of the discontinuous phase and the continuous phases [10]. Finally, the variation of viscosity as a function of different concentrations of the emulsions was introduced in 2001 [11$13]$.

\section{SET-UP}

In this paper, viscosity measurements of a SAE20W40 mineral oil sample are presented with the use of a Brookfield DV-III viscometer. The dependence on different temperatures in the pure state and in the presence of organic impurities and water is investigated and results are presented and discussed. The rotational viscometer used (Brookfield DV-III) is shown in Figure 1. As shown, a cylindrical container contains viscous oil. This cylinder, movable on its axis of cylinder rotation, is driven by oil. 
Before measurements are conducted, a calibration of the viscometer is performed using a non-Newtonian fluid (Glycerin) at room temperature, in order to find the important working parameters Brookfield DV-III. Figure 2 shows the variation of the dynamic and kinematic viscosity depending on the temperature $\mathrm{T}$ and the number of revolution per minute (RPM).

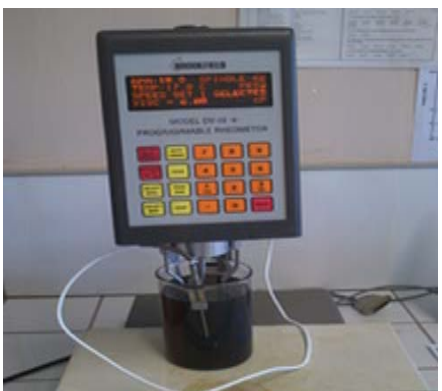

Fig. 1. Brookfield DV-III

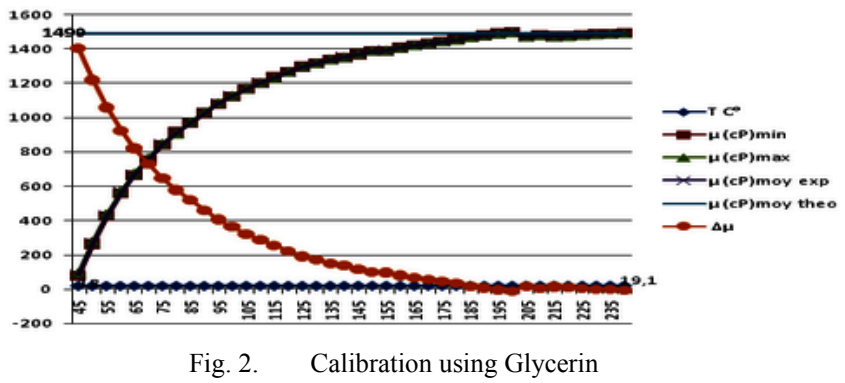

III. RESULTS AND DISCUSSION

Figures 3 and 4 show the curves for the new oil and the oil with impurities. A decrease in the dynamic viscosity and the kinematic viscosity for the two heterogeneous oils is noticed. The degradation rate is important for the mixing of oil with vapor. However, for the other oil mixture (water vapor and solid paraffin), an increase in viscosity was noticed compared to the oil mixed with water vapor for $70 \leqslant \mathrm{RPM} \leqslant 185$. Furthermore, after a certain $\mathrm{RPM} \leqslant 185$, it was noted that the curve thereof is almost coincident with the oil and water into steam. This should be attributed to the turbulence relaxation phenomenon created by the rotating cylinder.

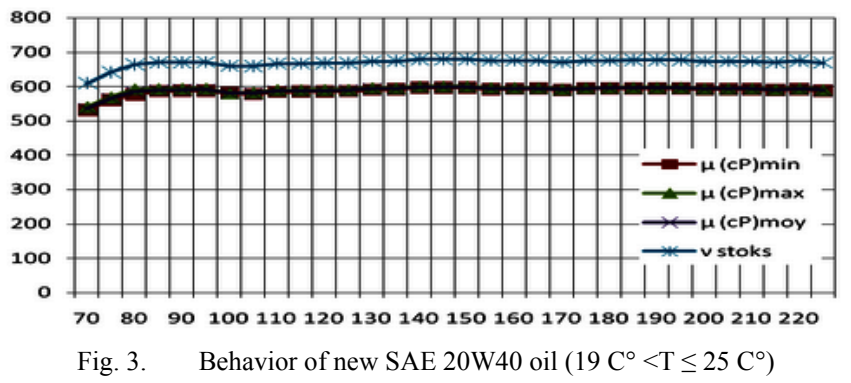

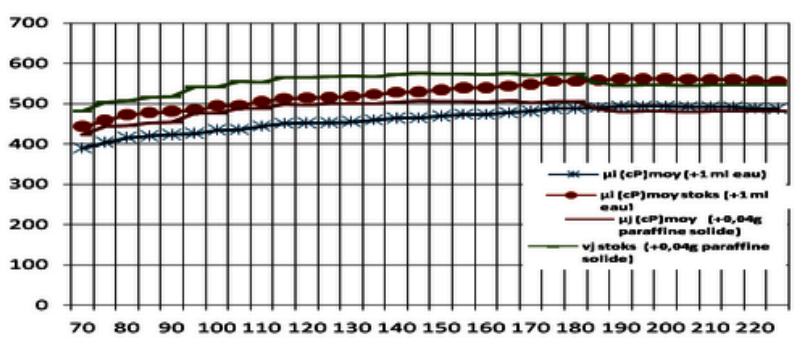

Fig. 4. Behavior of SAE $20 \mathrm{~W} / 40$ oil in the presence of organic impurities and water $\left(19 \mathrm{C}^{\circ}<\mathrm{T} \leq 25 \mathrm{C}^{\circ}\right)$

In order to define the effect of temperature on the kinematic viscosity, it is necessary to determine the constants A and B, discussed in ASTM D341 [6], based on the data of Figure 5 [14], considering (1):

$$
\log (\log (v+0,7))=A-B \log (T+273.15)
$$

The viscosity number (VN) has been recently proposed in the characterization of the performance of lubricating oils. By applying (1) we can determine the viscosity number for different states of changes in SAE 20W40. B values are inserted in (2) [7]. The NV values are shown in Table I.

$$
\mathrm{NV}=(1+((\mathrm{B} * 3.55) / 3.55)) * 100)
$$

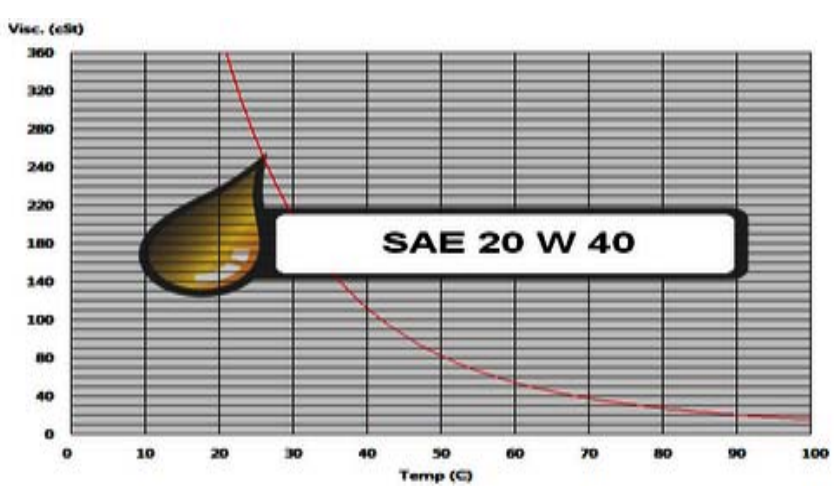

Fig. 5. SAE 20W40 Variation in function of temperature

TABLE I. VISCOSITY NUMBERS

\begin{tabular}{|c|c|c|c|}
\hline & SAE20W40 & SAE20W40+ water & $\begin{array}{c}\text { SAE20W40 } \\
\text { +water } \\
\text { +paraffin }\end{array}$ \\
\hline $\mathrm{NV}$ & 424.7519 & 406.9362 & 401.6023 \\
\hline
\end{tabular}

\section{CONCLUSION}

The SAE20W40 oil was mixed with water in the vapor phase and then with solid paraffin. Results show that there is a decrease in the dynamic and kinematic viscosity for heterogeneous oils. Their behavior was investigated in terms of viscosity in relation with temperature and rpm. The addition of paraffin in the mixture caused an increase in viscosity for smaller RPM but the results were similar for larger RPM. This 
relaxation phenomenon is attributed to the turbulence created by the rotational viscometer cylinder.

\section{ACKNOWLEDGMENT}

The authors wish to thank the National Agency for the Development of University Research (ANDRU) in Algeria for its support.

\section{REFERENCES}

[1] IUPAC, Compendium of Chemical Terminology, Gold Book, 2nd ed., 1997

[2] E.W. Dean, G.H.B. Davis, "Viscosity variations of oils with temperature, 'Chemical and. Metallurgical Engineering, Vol. 36, No. 10, pp. 618-619, 1929

[3] E.W. Hardiman, A.H. Nissan, "A Rational Basis for the Viscosity Index System", Journal of the Institute of Petroleum, Vol. 31, pp. 255-270, 1945

[4] M. A. Farah, R. C. Oliveira, J. N. Caldasa, K. Rajagopa, "Viscosity of water-in-oil emulsions: Variation with temperature and water volume fraction", Journal of Petroleum Science and Engineering, Vol. 48, No. 34, pp.169-184, 2005

[5] H. P. Ronningsen, "Correlations for predicting viscosity of w/oemulsions based on North Sea crude oils", SPE International Symposium on Oilfield Chemistry, 14-17 February, San Antonio, Texas, USA, 1995

[6] American Society for Testing and Material, Annual Book of ASTM Standards, Vol. 05, Philadelphia, USA 2001

[7] P. T. Cummings, D. J. Evans, "Nonequilibrium Molecular Dynamics Properties and Non-Newtonian Fluid Approaches to Transport Rheology", Industrial \& Engineering Chemistry Research, Vol. 31, pp.1237-1252, 1992

[8] Society of Automotive Engineers, SAE handbook, Vol. 124, 1968

[9] http://www.maths.usyd.edu.au/u/UG/SM/MATH3075/r/Einstein_1905.p df

[10] I. M. Krieger, T. J. Dougherty, "A mechanism for non-Newtonian flow in suspensions of rigid spheres", Transaction of the Society of Rheology, Vol. 3, pp. 137-152, 1911

[11] R. Pal, "Evaluation of theoretical viscosity models for concentrated emulsions at low capillary numbers", Chemical Engineering Journal,Vol. 81, No. 1-3, pp. 15-21, 2001

[12] G. I. Taylor, "The viscosity of a fluid containing small drops of another liquid”, Proc. R. Soc.,,A 138, pp. 41-48, 1932

[13] Walther, The evaluation of viscosity data. Erdol und Teer,V.7, pp.382384,1931

[14] Oil-Power Ltd, ViscCalc 2, available at http://www.oil-power.com/ 